\title{
Calcium Ion Selective Electrode Based On Surface Modified Zeolite Based lonophore \& Its Analytical Application
}

\author{
A.VIJAYALAKSHMI ${ }^{1}$ and J.THAMARAI SELVI ${ }^{2}$ \\ Department of Chemistry, Avinashilingam Institute for Home Science and \\ Higher Education for Women, Coimbatore- 641043, Tamilnadu, India.
}

http://dx.doi.org/10.13005/ojc/330147

(Received: December 19, 2016; Accepted: December 30, 2016)

\begin{abstract}
A new, efficient Calcium ion selective electrode has been prepared using Surface modified Zeolite based ionophore. The prepared ionophore is characterized by UV,FT-IR,XRD.. The sensor exhibits a near Nernstian response for $\mathrm{Ca}$ (II) ion over a concentration range of $1.0 \times 10^{-4} \mathrm{M}$ to 1.0 $M$. The proposed sensors revealed relatively good selectivity and high sensitivity for $\mathrm{Ca}(\mathrm{II})$ over a monovalent cations. It can be used with in the $\mathrm{pH}$ range of 5.57 to 6.24 . The effect of medium and the selectivity coefficient values was evaluated using fixed interference method found to give a better response. . It was also successfully used in the analysis of concentration of Calcium ion in various real samples.
\end{abstract}

Keywords: Calcium (II),Surface modified Zeolite, Potentiometry, Selectivity coefficient.

\section{INTRODUCTION}

The introduction of new ion-selective electrodes has played a fundamental role in the development of various sensory elements according to the charge and size of the target ion in clinical and environmental assays ${ }^{1-8}$. Potentiometric methods using ISEs for determining the metal ion have been studied extensively due to their importance in biological process ${ }^{9,10}$, easy handling, nondestructive analysis and in expensive sample preparation, applicability to coloured sample and turbid solution.
Calcium is the major element in the body. It plays a Vital role in the formation of bone, neuro muscular function, coagulation \& membrane permeability. In plants it helps in transpiration which leads to growth of the plant.

Bedlechowicz et al; 2002 developed calcium ion selective electrode using ETH1001 as an ionophore. In 2004 Kumar \& Mittal developed a new Calcium ion selective electrode based on PVC membrane modified by a new ionophore dibenzo18-crown-6(DB18C6). 
Taking into consideration of all the above facts that a new simple ionophore such as surface modified zeolite have been used as an electroactive phase for the fabrication of $\mathrm{Ca}^{2+}$ ion selective electrodes. In the present study the electrode show good selectivity and reproducibility over $\mathrm{Ca}^{2+}$ ion and the results are presented in this paper.

\section{EXPERIMENTAL METHOD}

\section{Chemicals used}

Silicic acid, Reagent grade tetrapropyl ammonium bromide, tetrahydrofuran, Ethyl acetate, Dimethyl Acetamide, DMF, Dioctyl phthalate (DOP), Sodium tetra phenyl borate (NATBP), tetra hydro furan (THF) were obtained from E.Merck and can be used without further purification. Throughout double distilled ionized water used.

\section{Synthesis of ionophore}

$2 \mathrm{~g}$ of Silicic acid was mixed with $3.5 \mathrm{~g}$ of tetrapropyl ammonium bromide and $0.514 \mathrm{~g}$ of $\mathrm{NaOH}$
$\& 50 \mathrm{ml}$ of water. The above mixture was heated at $100^{\circ} \mathrm{C}$ for 5 hours. The white precipitate was obtained. The silica content of the precipitate was determined by evaporation method \& found to be $1.1 \mathrm{ML}^{-1} .1 \mathrm{~g}$ of the above precipitate was dissolved in $2 \mathrm{ml}$ of water and was mixed with a1.15 $\mathrm{M}$ aluminate solution $(1 \mathrm{ml})$ to adjust the $\mathrm{Si} / \mathrm{Al}$ molar ratio to $0.5 \mathrm{M}$. The mixed solution was heated at $80^{\circ} \mathrm{C}$ for 24 hours. The resulting reaction mixture was dried in a oven

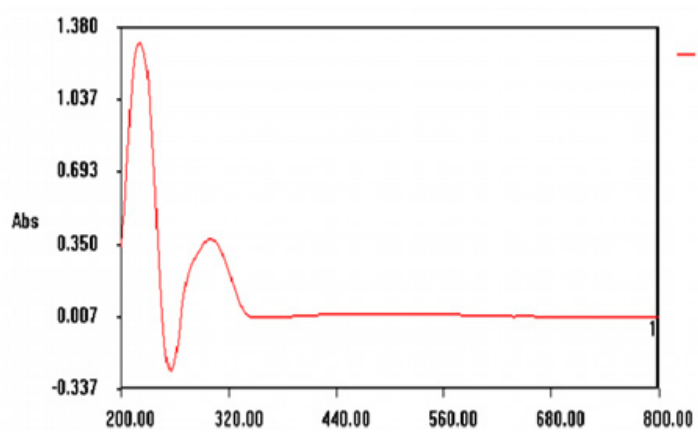

Fig 1: UV spectrum of the ionophore



Fig. 2: FT-IR Spectrum of the ionophore 
at $60^{\circ} \mathrm{C}$ overnight. The surface modified Zeolite was prepared by mixing the above mixture with $100 \mathrm{mM}$ HDTMA solution \& stirred for 24 hours. The mixture was then centrifuged at $5000 \mathrm{rpm}$ for $20 \mathrm{~min} \&$ finally the mixture was dried.

Yield:2.5g,Melting point: $201^{\circ} \mathrm{C}$

\section{Physical measurements}

For recording UV \& Visible spectrum PC based UV double beam spectrometer 2202 was used. FT-IR spctra were recorded on a FT-IR spectrometer. (model Shimadzu prestige-21 series) X-ray diffraction (XRD) analysis was carried out

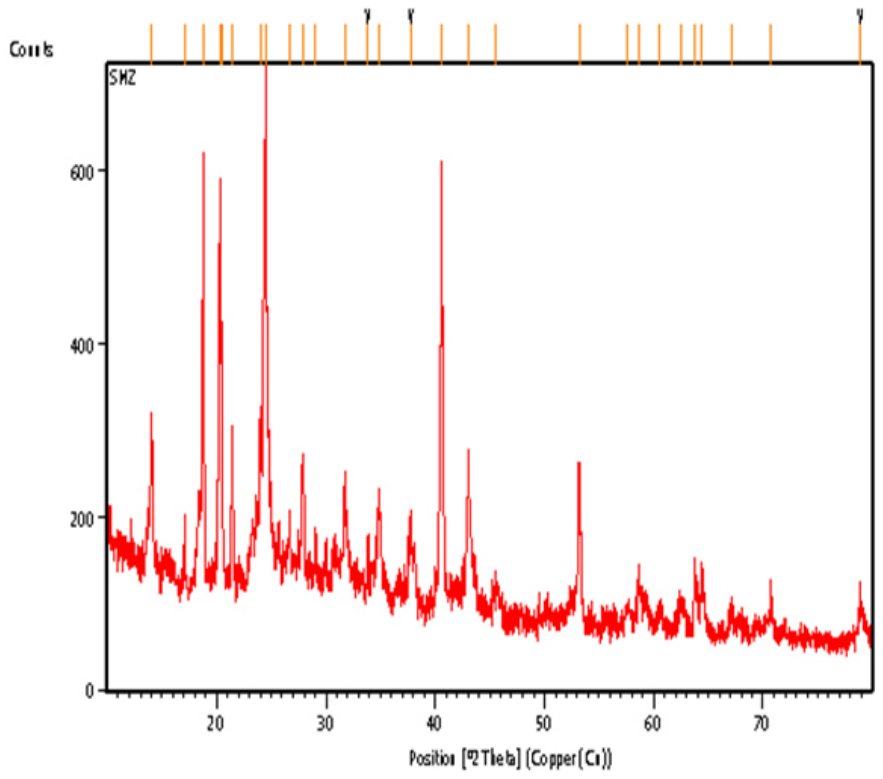

Fig. 3: XRD Spectrum of the ionophore



Fig. 4: Electrode response 
using PAN analytical x-Pert pro diffractometer from CuKá radiation (X-Ray tube PW 3050/60), In UV spectrum the peak at $221 \mathrm{~nm}$ corresponds to $\mathrm{CN}$ group (Pavian et al; 2001) fig-1. In FT-IR HDTMA Surfactant, Zeolite \& SMZ are shown in fig-2, The Zeolite absorbed frequencies are 501, 802, 1064, $1465,1635,2376,2970,3788 \& 3842 \mathrm{~cm}^{-1}$

SMZ showed frequencies are 462, 794, 1095, 1435, 1627, 2376, 2854, 2924, 3425, 3749, 3842 which indicate the incorporation of HDTMA on the Zeolite Surface.There was a slight shift in peaks at each wave numbere speically in the peaks at $1435,2854 \& 2924 \mathrm{~cm}^{-1}$ in the SMZ spectrum. This data confirmed the loading of HDTMA onto the Zeolite surface. (Nezamzadeh-Ejhieh and Mirzaeyan,2011)

Table 1: Electrode response

\begin{tabular}{ll}
\hline $\begin{array}{l}\text { Concentration } \\
\text { of } \mathrm{CaCl}_{2}(\mathrm{M})\end{array}$ & $\begin{array}{l}\text { EMF (Half Cell } \\
\text { Potential) volts }\end{array}$ \\
\hline 1 & 0.135 \\
$1 \times 10^{-1}$ & 0.044 \\
$1 \times 10^{-2}$ & -0.033 \\
$1 \times 10^{-3}$ & -0.083 \\
$1 \times 10^{-4}$ & -0.116 \\
$1 \times 10^{-5}$ & -0.116 \\
\hline
\end{tabular}

From X-ray diffraction study the composition was found to be $\mathrm{C}_{12} \mathrm{H}_{8} \mathrm{Cl}_{4} \mathrm{O}_{48} \mathrm{Si}_{24}$ in fig-3

\section{Fabrication of lon selective electrode}

A copper wire was polished with emery paper \& it was washed with distilled water \&THF. The copper was dipped into the concentrated solution $(0.3 \mathrm{~g}$ of ionophore $+0.1 \mathrm{~g}$ of DOP+PVC+3 $\mathrm{ml}$ of THF) for some minutes, so that a non-transparent coating was formed. The wire was taken out from the mixture and dried overnight. The electrode was finally conditioned to attain stable equilibrium for 10 days by dipping in $1 \mathrm{MCaCl}_{2}$. The electrode was kept in distilled water when not in use.

\section{Potential measurements}

All the membrane electrode potential measurements were performed at constant temperature $\left(30^{\circ} \mathrm{C}\right)$ using digital potentiometer (EQUIP-TRONICS EQ 602) in configuration with silver electrode as a reference electrode. The representation of electrochemical cell for the EMF measurement is as follows.

\begin{tabular}{lcc}
\hline Internal & Internal & External \\
Reference & reference & reference \\
Electrode & $\left(1 \mathrm{M} \mathrm{CACL}_{2}\right.$ & electrode \\
(Immobilised & Solution) & $(\mathrm{AG} / \mathrm{AGCL})$ \\
Cu wire) & & \\
\hline
\end{tabular}

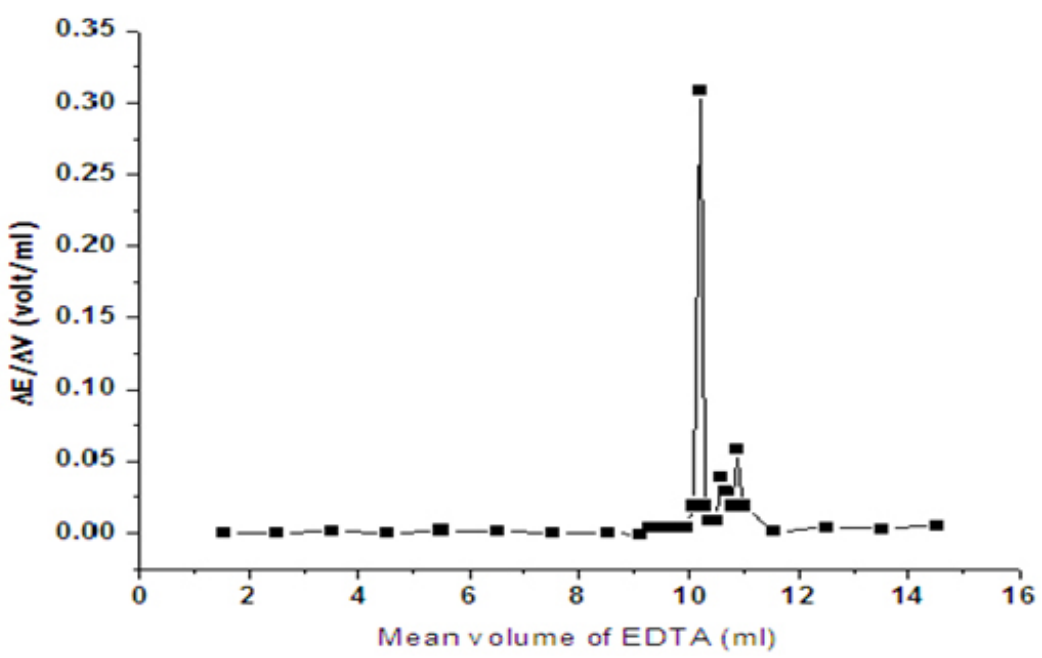

Fig. 5: EDTA Titration With Calcium 
Table 2: Effect of pH

\begin{tabular}{lccccc}
\hline $\begin{array}{l}\text { Conc (M) of } \\
\text { Ca }{ }^{2+} \text { ion }\end{array}$ & $\begin{array}{l}\text { E.M.F (Half cell } \\
\text { potential) Volts }\end{array}$ & $\mathbf{P}^{\mathrm{H}} \mathbf{3 . 4 2}$ & $\mathbf{P}^{\mathrm{H}} \mathbf{4 . 6 3}$ & $\mathbf{P}^{\mathrm{H}} \mathbf{5 . 5 7}$ & $\mathbf{P}^{\mathrm{H}} \mathbf{6 . 2 4}$ \\
\hline 1 & 0.135 & -0.067 & 0.109 & 0.133 & 0.139 \\
$1 \times 10^{-1}$ & 0.044 & -0.037 & -0.006 & 0.041 & 0.048 \\
$1 \times 10^{-2}$ & -0.033 & -0.114 & -0.094 & -0.04 & -0.028 \\
$1 \times 10^{-3}$ & -0.083 & -0.117 & -0.096 & -0.008 & -0.080 \\
$1 \times 10^{-4}$ & -0.116 & -0.117 & -0.101 & -0.090 & -0.080 \\
\hline
\end{tabular}

Table 3 :

\begin{tabular}{|c|c|c|c|c|c|c|c|c|c|c|}
\hline $\begin{array}{l}\text { Conc. } \mathrm{Ca}^{2+} \\
\text { Solution (M) }\end{array}$ & E.M.F & $\begin{array}{c}\text { Acetone } \\
25 \% \text { (Volts) }\end{array}$ & $\begin{array}{c}\text { Acetone } \\
50 \%\end{array}$ & $\begin{array}{c}\text { Acetone } \\
75 \%\end{array}$ & $\begin{array}{c}\text { Ethanol } \\
25 \%\end{array}$ & $\begin{array}{c}\text { Ethanol } \\
25 \%\end{array}$ & $\begin{array}{c}\text { Ethanol } \\
75 \%\end{array}$ & $\begin{array}{l}\text { DMA } \\
25 \%\end{array}$ & $\begin{array}{l}\text { DMA } \\
50 \%\end{array}$ & $\begin{array}{l}\text { DMA } \\
75 \%\end{array}$ \\
\hline 1 & 0.135 & 0.129 & 0.146 & 0.195 & 0.013 & 0.136 & 0.140 & 0.137 & 0.145 & 0.164 \\
\hline $1 \times 10^{-1}$ & 0.044 & 0.038 & 0.022 & -0.103 & -0.036 & -0.042 & 0.051 & 0.050 & 0.067 & 0.0981 \\
\hline $1 \times 10^{-2}$ & -0.033 & -0.034 & -0.030 & -0.063 & -0.114 & -0.033 & -0.029 & -0.031 & -0.025 & -0.021 \\
\hline $1 \times 10^{-3}$ & -0.083 & -0.083 & -0.121 & -0.038 & -0.078 & -0.110 & -0.089 & -0.081 & -0.083 & -0.012 \\
\hline $1 \times 10^{-4}$ & -0.116 & -0.121 & -0.056 & -0.091 & -0.042 & -0.102 & -0.081 & -0.119 & -0.051 & 0.002 \\
\hline
\end{tabular}

Table 4:

\begin{tabular}{ll}
\hline Cations & Selectivity co-efficient values \\
\hline $\mathrm{Na}+$ & $3.2 \times 10^{-5}$ \\
$\mathrm{~K}+$ & $6 \times 10^{-5}$ \\
\hline
\end{tabular}

RESULTS AND DISCUSSION

Working concentration range and slope of $\mathrm{Ca}^{2+}$ sensor

Electrode response

The electrode potential for a series of standard solution of $\mathrm{Ca}$ (II) ions was measured using potentiometer. The electrode gave a linear response to $\mathrm{Ca}$ (II) ion concentration range of $1 \mathrm{M}$ to $1 \times 10^{-4} \mathrm{M}$. The values are given in Table-1.Standard Electrode potential $\left(\mathrm{E}^{0}\right)$ was determined by standard methods (Gurtu and Gurtu,2011) at $25^{\circ} \mathrm{C}$, it was found to be $0.023 \mathrm{~V}$. The slope value was obtained from the calibration curve fig- 4 \& it was found to be $33 \mathrm{mv} /$ decade.

\section{Effect of ph on electrode response}

The effect of $\mathrm{pH}$ on the response of electrode was studied in this work. The electrode potential of standard $\mathrm{Ca}$ (II) solution of varying $\mathrm{pH}$ had been measured. It was found that the electrode worked well over a pH range of 5.57to 6.24 Table 2.

\section{Effect of Medium}

The influence of the electrode was also investigated in a partially non-aqueous media using $25-75 \%$ water-acetone, water-DMA, \& water-ehanol. The working non-aqueous media of the electrode was found to be $25 \%$ acetone medium, DMA medium in the conc of $10^{-4} \mathrm{M} \mathrm{Ca}^{2+}$ ion. $50 \%$ of ethanol medium in the concentration range of $10-2 \mathrm{M}$ of $\mathrm{Ca}^{2+}$ ion.

\section{Selectivity}

The potential response of the prospoed electrode to common cations were investigated by fixed interference method. (Semi-empirical NicolskiEisenmans equation). It was found that the potential remains unaffected in the presence of $\mathrm{Na}^{+} \& \mathrm{~K}^{+}$ cation.

\section{Analytical applications}

The new prepared electrode was successfully used as an indicator electrode for EDTA titration with $\mathrm{Ca}^{2+}$ ions in the laboratory. (Fig-5). 


\section{REFERENCES}

1. Shamsipur.M , Soleymanpour.A, Akhond.M, Sharghi,.H and Massah, A.R"Uranyl selective PVC membrane electrodes based on some recently synthesized benzo-substituted macrocyclic diamides," Talanta,2002, 58,2, 237-246,

2. ZhangZ.R and Yu,R.Q "The synthesis and membrane transport characteristics of macrocyclic polyether ligands composed of 1,10-phenanthroline as carriers for primary amine species," Talanta, 1994.41, 2, . 327333, .

3. Singh,A.K Saxena.P Mehtab.S and Gupta.B "Strontium(II)- selective electrode based on a macrocyclic tetraamide," Talanta,2006 . 69, 2 , .521-526,

4. Singh, A.K Saxena,P and Panwar, A"Manganese(II)-selective PVC membrane electrode based on a pentaazamacrocyclic manganese complex," Sensors and Actuators B,2005 . 110, 2 .377-381.

5. Ganjali, M.R, Razavi,T , Dinarvand,R, Riahi,. Sand Norouzi.P "New diltiazem potentiometric membrane sensor stands on theoretical calculations as a useful device for diltiazem hydrochloride analysis in pharmaceutical formulation and urine," International Journal of Electrochemical Science,2008, . 3, . 1543-1558,

6. GanjaliM.R, Memari.Z Faridbod.F and Norouzi.P "Samarium microsensor: an asymetric potentiometric membrane sensor," International Journal of Electrochemical Science, 2008 . 3, .1169-1179.

7. Beheshti S.S, and AminiM.K, "A simple and selective flow injection potentiometric method for determination of iodide based on a coated glassy carbon electrode sensor," International Journal of Electrochemical Science,2007. 2,778-787,

8. Zhang.H, Zhang.Z, Li.J and Sh. Cai, "Effects of Mg2+ on supported bilayer lipid membrane on a glassy carbon electrode during membrane formation," International Journal of Electrochemical Science,2007,2,. 788-796,

9. Paker.P, McGraw-Hill Concise Encyclopaedia of Science and Technology,1994 McGrawHill, New York, NY, USA,

10. D'Souza,.S.F,"Microbial biosensors," Biosensors and Bioelectronics, 2001,16, 6, 337-353, 